\title{
OP HOM DIE GROOT HOSANNAS - PERSPEKTIEWE OP DIE BEWARING EN VERNUWING VAN DIE KERKLIED
}

\section{J A Vos en T Gouws}

\section{ABSTRACT \\ HIS ARE THE GREAT HOSANNAS - PERSPECTIVES ON CONSERVATION AND RENEWAL OF THE CHURCH HYMN}

Throughout the ages until the present day the Christian Church has been committed to the Biblical, theological and ecclesiastical tradition in which the hymns and anthems served to express and interpret its faith. The conservation of a rich hymnological tradition has not restrained the Church to strive for renewal of the hymnal. This pursuit is based on the insight that hymnological renewal is necessary from a theological and practical point of view. In this article certain theological, literary and musicological perspectives are presented on the duality between hymnological conservation and renewal.

\section{Bewaring en vernuwing}

In die Psalmboek het die lied in tye van bedreiginge (Ps. 3-5), in lewensgevaar (Ps. 6, 88), in groen weivelde, in donker dieptes (Ps. 23) en in die Here se heiligdom (Ps. 15, 24) die mens se ervaring van sy verhouding met God verklank. Die verhouding met God word in die Psalms deur 'n verskeidenheid stemminge vertolk: lof, aanbidding, dank, voorbidding, klagte, seën en vloek, oorwinning en wysheid."

Verskillende liedsoorte kom óók in die Nuwe Testament voor. Daar is die drie Cantica, die lofgesange: die magnificat, die lofgesang van Maria (Luk. 1:46-55); die benedictus, die lofgesang van Sagaria (Luk. 1:68-79) en die nunc dimittis, die lofgesang van Simeon (Luk. 2:29-32). Paulus siteer waarskynlik in Efesiërs 5:14 woorde uit 'n dooplied $^{2)}$ wat soos volg lui:

"Word wakker, jy wat slaap,

en staan op uit die dood;

en Christus sal jou lewe verlig".

In Efesiërs 5:19 is daar van drie soorte liedere sprake: psalms, lofgesange en geestelike liedere. Die Openbaringboek berig ook van 'n reeks liedere $(4: 11 ; 5: 9-10,12-14 ; 7: 12 ; 14: 3 ; 15: 3-4)$ wat Johannes visioenêr beleef het.

Selfs nie-Christelike getuienis lewer bewys van die sentrale plek van die lied in die oer-Christelike gemeente. Die Romeinse stadhouer Plinius (111-113) skryf 'n brief aan die keiser Trajanus waarin hy hom meedeel dat hy tydens ' $n$ verhoor niks nadelig van die Christene kan getuig nie. Waarvan hy egter wel melding maak, is dat hulle op 'n 
onskadelike wyse bymekaar kom en vir Christus as hulle God liedere sing (Carmen Christo quasi deo dicere). ${ }^{3}$

Deur die eeue tot vandag toe is die Christelike kerk verbind aan die Bybelse tradisie waarin die lied 'n uiting en vertolking van geloof in God is. ${ }^{4)}$ Die omdigting waarmee die drie Afrikaanse kerke tans besig is, is ' $n$ bevestiging hiervan. Die erfenis van die verlede blyk onder andere deur die melodieë van die Geneefse Psalmbundel van 1562 (bv Ps. 1, $3,4,5,6,15,16,42,43,66,68,84,89,116$ en 121), asook dié van Martin Luther (Ps. 28, 46, 64, 82 en 104) wat in die Psalmbundel neerslag gevind het. In die Gesangebundel het Gesange van Martin Luther (Gesang 75, 106, 137, 218, 240, 303, 345), J Neander (Gesang 45, 311), en Ph Nicolai (Gesang 66, 113, 166, 204, 213, 239, 275, 285) 'n plek gekry.

Die verbinding aan 'n ryk himnologiese tradisie weerhou egter die Nederduitse Gereformeerde Kerk nie daarvan om na vernuwing te soek nie. In 1986 het die Algemene Sinode van die Nederduitse Gereformeerde Kerk besluit dat ' $n$ proefsangbundel gereed gemaak moes word. Die opdrag was om soveel moontlik liedere uit die Jeugsangbundel op te neem; ook die Halleluja weer onder oë te neem; liedere wat eietyds aanspreek, te vind; veral te voorsien in die behoeftes van die jeug. ." $^{\text {(1) }}$

Die opdrag wortel in die besef dat vernuwing in die erediens ' $n$ teologiese en praktiese noodsaaklikheid is. Teologies gesien is die liturgie ' $n$ dinamiese begeleier van die erediens. Daarom vra die liturgiese momente steeds om verantwoorde vernuwing. Op himnologiese vlak beteken vernuwing nie net die vinding van die eietydse lied nie, maar liedere wat die eeue oorleef het moet ook opgespoor word. Wanneer ' $n$ kerk op hierdie wyse deur vernuwing liedere invoeg wat dwarsoor die wêreld gesing word, sing hy in die koor van die algemene Christelike kerk. ${ }^{6)}$ Op prakties-godsdienstige vlak het die gemeente behoefte daaraan om God met nuwe klanke en woorde te aanbid, te prys, te dank en te dien. In ons tyd van sekularisasie en kerklosheid is dit veral ook van belang om ' $n$ nuwe idioom en styl vir die kerklied te vind, want inderdaad is dit waar wat Ryden" opmerk: "hymn is a child of the age in which it was written". Wat Barnard ${ }^{(8)}$ dan in aansluiting hierby sê oor die Afrikaanse kerklied, vat die belangrikheid van vernuwing goed saam: "By die kerklied is daar juis die gevaar om te lank vas te hou aan 'n verbygegane kultuur, en aan die eie kultuur verby te leef". Die belangrikheid hiervan kan nie negeer word nie - daar moet haas 'n nuwe tradisie in die Afrikaanse kerkmusiek kom.

'n Ywer om vernuwing hef egter nie die spanning tussen vernuwing en bewaring op nie. Die spanning moet deur ' $n$ balans in ewewig gehou word. Die vind van 'n balans bestaan in die erns waarmee die himnologiese vernuwing aan teologiese, literêre en musikologiese vereistes gemeet word. 


\subsection{Teologies}

'n Teologiese beoordeling van die lied moet ruimte maak vir ' $n$ himnologiese ekklesiologie. Dit beteken dat die teologie die plek en die funksie van die gemeente ten opsigte van die lied in berekening moet bring. Dié uitgangspunt staan teenoor die middeleeuse dwaling wat die gemeente tot passiewe toeskouers gesnoer het. Die lied is die besitting van die gemeente ${ }^{91}$ waardeur diens aan God gelewer word. Daarom staan die funksies van die lied in die nouste samehang met die diens van die gemeente in die erediens.

In 'n himnologiese ekklesiologie kry die liturgie 'n nuwe speelruimte. Die lied is nie net ' $n$ versiering of ' $n$ opluistering van die erediens nie, maar dit is wesenlik deel van die erediens, verryk die erediens. Soos die melodie die aard van 'n lied aandui, so dra die lied ook die geloofsaard in die erediens. Dit sprei soos 'n aangename geur deur die erediens. Ook verruim die lied die erediens. Die lied weef die verskillende liturgiese momente in die erediens heg aaneen. Dit omring die preek: vóór die preek met lof, aanbidding en belydenis (van skuld en geloof), en ná die preek met toewyding en getuienis. Dit is nie net die preek wat ' $n$ verkondigende aard het nie; ook die lied het 'n verkondigende dimensie. ${ }^{10\}}$

In 'n himnologiese ekklesiologie moet daar ook rekenskap gegee word van die moontlikheid dat die lied 'n draer van afwykende teologieë kan wees. Daar is talle liedere waarin afwykende teologiese gesigspunte na vore kom. Hier word net op vier voorbeelde gelet. 'n Strofe van die eerste lied lui só:

\footnotetext{
"Komm, o Tod, du Schlafes Bruder, kommt, und führe mich nur fort; lose meines Schiffleins Ruder, bringe mich in sichern Port.

Es mag, wer da will, dich scheuen:

Du kannst mich viel mehr erfreuen:

Denn durch dich komm ich hinein zu Christo, dem Herren mein."
}

In dié strofe van 'n lied waarvan Johann Sebastian Bach (1685-1750) die komponis is, word die dood as die broer van die slapende voorgestel. Die broer word gevra om die gelowige voort te lei, en hierdie weg van die gelowige word deur 'n skeepsbeeld toegelig. Die een wat hom na ' $n$ veilige hawe bring, is derhalwe die dood. Gevolglik kan die dood ook as 'n bron van vreugde beskou word omdat hy die weg na Christus, die Here is. Hierdie voorstelling van die dood druis in teen die Bybelse getuienis. In die Bybel is die dood nie ' $n$ broer nie, maar die laaste vyand. Daar is maar Een wat die vyand oorwin het en wat die weg na die lewe is - Christus, ons Here (vgl. 1 Kor. 15 en Joh. 14:6). Daarom is $\mathrm{Hy}$, en nie die dood nie, ons Bron van vreugde. 
Die tweede voorbeeld van 'n verskraalde teologiese siening word deur die drie versreëls van 'n lied Jesu, meine Freude van Joh. Franck vertolk. Die versreëls lui soos volg:

\author{
"Weg mit allen Schätzen! \\ Du bist mein Ergetzen, \\ Jesu, meine Lust!"
}

In dié versreëls beluister ons ' $n$ wêreldmyding en die vrome se behae in Jesus alleen. Natuurlik is Christus die lewe vir die gelowige, maar die lewe hier moet geleef word. Toewyding aan Christus eis nie ' $n$ wegvlug uit hierdie wêreld nie, maar trou aan Hom in hierdie wêreld (vgl Joh.17).

Die lied Es glänzet der Christen inwendiges Leben van C.F. Richter (1704) is deur F.D.E. Schleiermacher in die Berlynse Gesangboek opgeneem. Die volgende twee strofes van die lied is draers van 'n afwykende teologie:

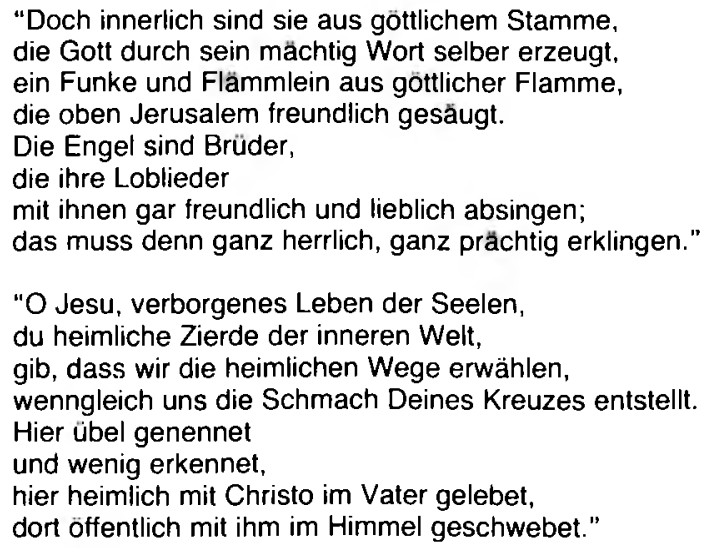

In die eerste strofe word daar gesing dat die Christen se innerlike uit die Goddelike stam. Die Christen se innerlike word 'n vonk en 'n vlammetjie uit die Goddelike vlam genoem. Dié siening wortel in 'n Grieksfilosofiese stroom dat die mens uit die gode voortvloei en weer na sy dood na hulle toe terugvioei. Dit staan ver van en vreemd teenoor die Bybelse getuienis dat God die mens na sy beeld gemaak het (Gen. $1: 26)$.

In die tweede strofe word Jesus as die verborge lewe van die siele en die sieraad van die innerlike wêreld besing. Hy moet ook die gelowige in staat stel om die heimlike weg te kies en om heimlik met Christus in die Vader te leef. Die innerlike wêreld word hier teenoor die uiterlike wêreld gestel met die bedoeling dat die uiterlike wêreld die sondige werklikheid is. Die eintlike werklikheid is nie op aarde nie, maar in die hemel verborge. Onmiskenbaar hier is die invloed van die Plato- 
nisme. Die gelowige se verhouding met Christus is volgens die Bybel ook nie 'n geheime verhouding nie, maar ' $n$ openbare verhouding wat in hierdie wêreld geleef en gesien word.

Die laaste strofe uit ' $n$ vierde lied kom uit die pen van Gerhard Tersteegen (1697-1769). Die lied is as Gesang 311 verwerk. In die Duitse teks lees die laaste strofe soos volg:

\author{
"Herr, komm in mir wohnen, \\ lass mein'n Geist auf Erden \\ dir ein Heiligtum noch werden. \\ Komm, du nahes Wesen, \\ dich in mir verkläre, \\ dass ich dich stets lieb und ehre. \\ Wo ich geh, \\ sitz und steh, \\ lass mich dich erblicken \\ und vor dir mich bücken."
}

In die tweede versreël word die menslike gees as plek van die Here se inwoning verklaar. Die rede hiervoor is geleë in 'n siening wat die liggaam geringskat. Dit vind plaas onder invloed van die Griekse filosofie wat die liggaam minag en die gees hoogag. Die Bybel daarenteen slaan die liggaam, omdat dit God se skepping is, hoog aan. ' $n$ Verdeling van die mens in 'n hoër (gees) en laer (liggaam) deel is volkome vreemd aan die Bybel. Volgens die Bybel is die mens 'n eenheid (Matt. 22:37). Die gelowige behoort as mens aan God. Daarom kan 1 Korintiërs 6:19 verklaar dat die gelowige se liggaam 'n tempel van die Heilige Gees is.

In die lig van die kerklied se diensfunksie in die liturgie moet die lied die gemeente sterk maak teen afwykende teologieë. Die lied kan dié funksie vervul as dit self aan teologiese eise voldoen. Wanneer dít die geval is, kan die lied as skildwag van die Bybelse boodskap dien. Die teenoorgestelde kan egter wel ook gebeur: deur die lied kan afwykende teologiese nuanseringe in die erediens ingesing word.

'n Himnologiese ekklesiologie moet ook rekenskap gee van die soort spiritualiteit in 'n gemeente. Die oorwinning oor die Griekse denke dat die mens in liggaam, gees en siel verdeelbaar is, het tot die insig gelei dat spiritualiteit nie net tot die geestelike lewe beperk is nie. Dit omvat die mens in sy totale bestaan. Die ervaringe wat mense daagliks meemaak, vind noodwendig neerslag in hulle ervaringe van die erediens. Himnologies gesproke het die lied 'n spirituele dimensie. Dit kan 'n gevestigde spiritualiteit bevestig, maar dit kan ook 'n vreemde spiritualiteit in die erediens insmokkel en die bestaande spiritualiteit verdag maak. Die gevestigde sowel as die vreemde spiritualiteit moet onder die teologiese soeklig kom. ${ }^{11}$

'n Lied kan so meevoerend wees dat dit maklik die gevestigde spiritualiteit kan kanoniseer en die vreemde spiritualiteit kan sanksio- 
neer. Die oogmerk is nie dat die gevestigde liedere soos mure moet verkrummel nie, maar dat dit die toets van die teologie moet deurstaan. Wanneer die gevestigde lied die gereformeerde spiritualiteit helder vertolk, moet dit gehandhaaf word. Gereformeerde spiritualiteit is 'n lewe wat onder invloed van die Heilige Gees en in die kragveld van die Woord van God, gerig is op diens aan God, die naaste en die wêreld. ${ }^{12}$ Wanneer die spiritualiteit ekkerig-sentimenteel vertoon, as dit heilsindividualisties gerig is, moet dit vermy word. ${ }^{13)}$ In die tyd van die piëtistiese hoogbloei (1680-1760) is die lied juis deur dié soort spiritualiteit gevoed. ${ }^{14)}$ ' $n$ Vreemde spiritualiteit wat die evangelie van Jesus Christus met sy goeie nuus van solus Christus, sola fide en sola gratia aantas, moet geweer word. As dit nie gedoen word nie, stempel dié soort spiritualiteit die ganse godsdienstige belewing van die mens. Dit is byna vanselfsprekend dat die teologiese worsteling met die lied as draer van verskillende soorte spiritualiteit 'n blywende opdrag aan die kerk is. Dit is ook die kwalifiserende vereiste waaraan die kerklied gemeet moet word.

\subsection{Literêr}

Die literatore se taak as deel van die reviseurs van die Afrikaanse Psalm- en Gesangeboek (1944) is indertyd só uitgespel: "Voldoen die aangenome berymings t.o.v. spelling, afkortings, uitdrukkings, sinsbou, punktuasie, ens. aan die eise van die Afrikaanse taal en estetiek?" ${ }^{15)}$ Dit is duidelik dat die liriek van die psalms en gesange eintlik bloot taalkundig ondersoek moes word; van estetiese beginsels is daar in die taakspesifisering nie sprake nie.

Die taak van die literatore ten opsigte van estetiese evaluering sou dalk meer direktief uitgestippel kon gewees het deur te stel dat die tekste moet voldoen aan die eise van die estetiek, volgens die HAT ${ }^{16}$ dié wetenskap wat die beginsels van skoonheid in die kuns probeer aantoon. Dit sou enersyds inhou die waardering van die skoonheid ${ }^{17}$, wat in eietydse terme die emosionele ${ }^{18)}$ resepsie genoem kan word, en andersyds ' $n$ analise van die teks gemeet aan bepaalde konsepte in die kuns, soos dieperliggende betekenis, representasie ${ }^{19)}$, konteks/verwysingsraamwerk en ikonisiteit, wat intellektuele resepsie genoem kan word. Albei maatstawwe is van groot belang en mag nie negeer word nie. Daar word immers in 1 Korintiërs 14:15b uitgespel: "Ek moet met die gees die lof van die Here sing, maar ook met die verstand".

Taalkundige korrektheid is ' $n$ noodwendigheid by die skep van 'n (literêre) teks, nie 'n aspek van estetiek nie. Daar bestaan ook nie iets soos estetiese/literêre taalgebruik nie, ${ }^{20)}$ eerder taal wat binne 'n emosionele en/of intellektuele aanbod waardering stimuleer, en derhalwe op estetiese/literêre waarde aanspraak kan maak.

Nietemin is en bly taal die voertuig van die boodskap, hoe dit ook al deur vooropstelling, verwysing, vervanging, ellips, sinsverband, lek- 
sikale en ander vorme van binding ${ }^{21)}$ in 'n teks gemanipuleer word in diens van die boodskap. Barnard ${ }^{221}$ se toegedane mening stel die saak in die regte perspektief: "Dit blyk dus dat die hele saak van die letterkunde en die kuns ter sprake kom by die maak van'n lied. Nooit mag dit egter gaan om die kuns ter wille van die kuns ${ }^{231}$ as sodanig nie. Tog kan die kuns in 'n dienende posisie nie misken word nie".

Gaum $^{24)}$ se omvattende ondersoek na die literariteit van die Afrikaanse evangeliese gesang ${ }^{25}$ het aangetoon dat dit leerstellig aanvaarbaar is, maar meermale literêr te kort skiet. Dit is so omdat die Revisiekommissie self baie gedigte probeer skryf of herskryf het en geen erkende digter enduit in die kommissie gedien het nie. "Die produk was dikwels 'skrifgetroue' dog onbesielde rymelary". ${ }^{26)}$

Gaum se literatuuropvatting was met die skryf van sy proefskrif in ooreenstemming met die konsep van literariteit in daardie tydperk. Om dié rede het hy sekere literêre vereistes gestel aan die gesang (soos aan die gedig): daar moet sprake wees van woordversorging, ritme, klankekspressie, harmonie en proporsie, simboliese uiting van 'n eie belewenis in sy algemeen-menslike betekenis, dramatiese krag, die onvervangbare woord, die eenheid van vorm en inhoud, die raak beeld, besielde retoriek en so meer. ${ }^{27)}$

Alhoewel dit duidelik is dat die maatstawwe vir die evaluering van literariteit van die kerklied bedoel is, is dit noodwendig ook voorgehou as riglyne vir die skep van lirieke. As Gaum ${ }^{28)}$ sê dat die literêre teks nie laslapwerk moet wees nie, ondermyn sodanige "literêre vereistes" sy opmerking, want dit werk dit juis aan die hand. Die digter, het Cloete $^{29 !}$ gesê, dink integraal. ${ }^{30}$ Om dié rede het W. E. G. Louw ${ }^{311}$ die volgende standpunt gemaak: "Aan die skeppende vermoëns van 'n kommissie het ek ... geen fidusie nie! 'n Kommissie kan kontroléér, kan kéúr; maar 'n veelkoppige kommissie kan nie skep of selfs herskep nie!. . . (D)ie skryf van ' $n$ vers is die werk van 'n digter, nie dié van 'n teoloog of 'n kommissie nie".

Omdat die digter integraal dink en skep, groei literariteit uit die teks; dit word nie daarop afgedruk nie. Derhalwe is die enigste literêre "eis" vir die skep én evaluering van 'n teks: kohesie. Halliday en Hassan, ${ }^{32}$ wat veel navorsing op dié vlak gedoen het, sien kohesie primér as semantiese verhoudinge in die teks. Verdere navorsing deur byvoorbeeld Beukes ${ }^{33 l}$ het aangetoon dat kohesie op al die vlakke van die teks werksaam is, met ander woord op konseptuele vlak (figure, gebeure, ruimte en tyd), taalmanifestasievlak (klank, ritme, sintaksis en woordbetekenis) asook komposisievlak en dat die integrale aanbod van al die kohesievorme as sodanig meewerk tot die vestiging van begrip. Indien die kohesie in ' $n$ teks uitgelees word, dit met ander woorde bydra tot die verstaan van die geheel, word dit koherensie genoem.

Die kohesie en koherensie is ook op 'n praktiese vlak belangrik. ' $n$ Lied, veral die kerklied, is ' $n$ kunsvorm wat in tyd ontvou. Die gemeente- 
lid word deur die musiek meegesleur en as't ware "gedwing" om in pas te bly. Dit hou in dat die kennismaking met die liriek as sodanig momenteel en vlugtig is; om enigsins te verstaan wat gesing word, moet dit onmiddellik toeganklik wees. Nou weet ons ook dat taal altyd binne 'n bepaalde verwysingsraamwerk of konteks gebruik word, en dit is hier waar kohesie die lidmaat "lei" tot die konstruering van betekenis, of dan: koherensie.

Dit is maklik om aan te toon hoe daar in 'n fyngestruktureerde (en dus literêre) teks kohesiebande gestig word; tog is dit miskien wensliker om eers aan te toon hoe 'n gebrek aan kohesie ernstige betekenisprobleme tot gevolg kan hê.

Kyk ' $n$ mens byvoorbeeld net na kohesie ten opsigte van figure in 'n teks soos Psalm 21:7, waar staan:

"Hul somervrug, hul lenteblom,

hul kroos sal U verderwe;"

Die herhalende kohesiewe klem op hul (drie keer), wat in dié strofe in elk geval ook nie na iemand spesifiek verwys nie, aksentueer die hul se belangrikheid; derhalwe is die eerste onmiddellike betekenisverband dat die hulle se kroos God sal verderwe, 'n totaal verkeerde agensplasing. ('n Mens sou ook logieserwys wou vra: kom lenteblom nie vóór somervrug nie? Hier is dus ook semanties gesien 'n swak kohesiewe relasie in dié versreël). Dieselfde gebeur in Psalm 22:10, wat só lui:

"Die Heer het nooit in die bekommernis

verag, verfoei hom wat ellendig is:

toe hy geroep het, was sy antwoord wis."

Omdat die versreëleinde van die eerste reël nie die werkwoord insluit nie, veroorsaak die pouse dat die nooit nie kohesief koppel nie, en daarom lees versreël 2 selfstandig, en sê dit presies die teenoorgestelde as wat bedoel is.

Die woordjie wis - soos hy hier gebruik word - is taamlik vreemd. Wie, sou 'n mens kon vra, sou dié woord in die middel van 'n strofe dadelik kon lees as "seker", of "stellig". Eerder, uit die gebruikskennis van die taal, sou die gemiddelde lidmaat die woord - al sou dit woordsoortlik dalk nie heeltemal pas nie - interpreteer as "uitvee". Dít sal óók die teenoorgestelde betekenis tot gevolg hê. Dié is dan 'n voorbeeld van gebrekkige kohesie op woordbetekenisvlak. In die res van die strofe is daar betekenismatig gesien géén binding wat sou kon help om in die kort realisering van die teks die begrip te ondersteun nie. Alle argaiese woorde (bv. swerk, gerubs, transe, nuw're, en so meer) - en hoe wemel dit nie hiervan in ons sangbundels nie - dra by tot die verwarring. 
'n Laaste voorbeeld uit die proefsangbundel Sing onder mekaar ${ }^{34)}$ om probleme ten opsigte van sintaktiese kohesie aan te toon. ' $n$ Deel van lied 8 lui só:

3 "Wie selfgerig bly lewe, hy sal homself verloor

4 maar wie aan selfsug sterwe, laat loop die Leidsman voor.

5 Die Heer vra ons almal dat ons onsself verloën:

6 net só kan ons aan ander sy reg, sy trou betoon.

7 Want elkeen wat die lewe net vir homself wil hou,

8 is aan die blye boodskap, die Lewe self, ontrou.

9 Die Leidsman na die lewe het deur wat Hy moes ly 10 vir ons 'n doel op aarde - werk in sy ryk - berei."

Binne die bekende konteks van Matteus 16:24-27, veral vers 25 wat sê: "want wie sy lewe wil behou, sal dit verloor; maar wie sy lewe ter wille van My verloor, sal dit terugkry", word dié Skrifberyming gesing. Die gemiddelde kerkganger, sou 'n mens meen, begryp (in watter mate dit moontlik is!) die paradoks van dié Skrifgedeelte; sing hy egter die beryming (veral reëls 3 en 4), veroorsaak sy Bybelkennis hier by wyse van spreke sy begripstruikeling. Wie selfgerig lewe, verloor homself, sê die beryming, maar dan weet hy as gelowige: as hy homself verloor (in Christus), sal hy sy lewe terugkry. Dié indruk word versterk as reël 4 begin met maar, wat sintakties die teendeel gaan inlei, en dan stel: "wie aan selfsug sterwe", wat met die eerste singlees móét geïnterpreteer word as sou dit beteken: dood vanweë graad van selfsug (vgl. "wie aan kanker sterwe"). Hierdie interpretasie is nie die gevolg van foutiewe Skrifuitlegging nie, maar 'n gebrek aan sintaktiese kohesie. Dit het noodwendig 'n negatiewe effek op begrip.

Net enkele ander inkongruensies ter illustrasie. Die oormatige herhaling en vooropstelling van ons in reëls 5 en 6 ("dat ons" kan byvoorbeeld gemaklik deur iets anders vervang word) is juis teenstrydig met die verloëning van die ek wat gevra word. 'n Mens sou dit kohesiewe inkongruensie kan noem. Ook pla byvoorbeeld die paranteses in reëls 7 en 10 - nie net is daar probleme op sintaktiewe kohesievlak nie, maar dit bring ook betekenisverwarring mee.

Die probleem van die tekste hierbo (die sintaktiese nagmerries van tekse soos Psalm 22 maar eers daar gelaat), lê in die geklonterde taal wat nie kohesief bind nie en daarom nie koherent gerealiseer kan word nie. Wellek en Warren ${ }^{35}$ ) se beswaar teen "( $p$ )oems of closely knit, highly integrated structure" is nie 'n beswaar teen kohesie nie, maar teen geklonterde taal. Tekste van dié aard "do not lent themselves to musical setting". En dit bring ons by seker die knellendste probleem in die spanning tussen bewaring en vernuwing van die kerklied. 
Die kerklied soos ons hom vandag ken en sing, het sterk historiese wortels. In die voorwoord tot Die berymde psalms en die evangellese gesange word onomwonde gestel dat daar gevoeligheid was vir die Geneefse tradisie van die psalms, en dat "'n (s)tuk kultuurgoed uit die tyd van die Reformasie... via die Nederlandse Psalmboek ook vir ons behoue gebly (het)". Selfs met die proefsangbundel was dit die geval. Van die 47 liedere daarin opgeneem, is hoogstens 8 nuwe melodieë. Die res, soos dit ook met die Psalm- en Gesangeboek die geval is, is tradisionele melodieë. Daarvoor is Afrikaanse tekste geskep, of soos Gaum ${ }^{36)}$ dit noem - taal in 'n "keurslyf ingedwing". Die proses behoort andersom te verloop: digters moet gebruiksliriekstekste skep, en dié moet dan getoonset word. Helaas is dit wat Van Heerden ${ }^{37)}$ sê ten séérste waar: "Ons Gesange (maar óók ons psalms - CJAV \& TG) is nog te min primêr uit Afrikaanse bodem, eg en deurleefd".

'n Struikelgat waarin veel berymers, vertalers en liriekskrywers geval het, was juis om met 'n sogenaamde "literêre" hand bepaalde "literêre" kwaliteite op die teks af te druk. 'n Wyer beskouing van literariteit, hier gekulmineer in die resepsieteoretiese werking van kohesie en koherensie, het aangetoon dat - soos aan die begin van die afdeling gestel is - estetiese waardering gelee is in emosionele en intellektuele respons. En dít kan nét verkry word as die teks onmiddellik toeganklik ${ }^{38)}$ is; binne die bevattingsvermoë van letterkundig en musikaal ongeskooldes. ${ }^{39)}$

\subsection{Musikologies $^{40)}$}

Net soos in taal kom verskynsels van frasering, sinsopbou, klimaks, ritme, punktuasie, aksentuasie, progressie asook woordskildering soos hoog en laag en daling in musiek voor. Die musikale semantiek beoog om die melodie as waardige draer van die teks te laat optree. Dit beteken dat die melodie die teks so getrou as moontlik moet weerspieël. 'n Hegte woord/toon-verhouding wat die lied natuurlik laat vloei, moet nagestreef word. Die verhouding vereis dat die literêre en musikale frasering, die klimakse, die aksentpunte, die kadenspunte (volmaakte of onvolmaakte kadens) moet harmonieer. Die dienende funksie van die musiek moet daarop gerig wees om die gemeente in staat te stel om hom met die teks te identifiseer, en hom met die sing daarvan uit te leef. Soos met Saul die geval was (1 Sam. 16:23) moet die pastorale rol van musiek nie uit die oog verloor word nie.

Die identifikasie vind plaas wanneer die gemeente deur die melodie tot oorgawe aan die teks beweeg word. Dit beteken dat daar sekere eise aan melodieë vir kerkmusiek gestel moet word. Die melodie moet die inhoud van die teks so laat spreek dat dit die totale mens, emosioneel en intellektueel, tot oorgawe oorreed. Dit kan slegs gebeur as die melodie oor 'n sin(g)ryke struktuur beskik. ${ }^{41)}$ Melodieë moet nie 'n te groot stem-omvang hê nie. Dit moet deur kinders, mans en vrouens 
ewe maklik gesing kan word. ${ }^{42)}$ Daar moet gewaak word teen moeilike klinkers (bv ie en oe) op hoë note. Melodiese wendinge of harmoniese progressie gaan die vermoë van die deursnee lidmaat gewoonlik te bowe. ${ }^{43)}$ Daar moet gebalanseerde spannings- en ontspanningskurwes asook duidelike klimakspunte in melodieë ingebou wees. Op dié wyse word 'n natuurlike voortstuwing verseker. Sinvolle melodiese herhalings en sekwense help om die melodie in die geheue van die kerklidmaat te vestig. ${ }^{44)}$

Aandag aan die ritmiese struktuur bring mee dat daar oorwegend van basiese nootwaardes gebruik gemaak moet word met 'n goeie balans tussen korter en langer nootwaardes. Die melodieë moet nie ingewikkelde ritmiese elemente bevat nie. Dit beteken egter nie dat sinkopes en onreëlmatige patrone nie aangewend mag word nie, maar wel dat die ritmiese struktuur die singbaarheid van ' $n$ melodie moet verhoog. Naas die vermyding van te ingewikkelde ritmiese elemente moet maatsoorte en ritmiese patrone wat geassosieer word met, of kenmerkend is van bepaalde dansvorme (bv. die wals) nie gebruik word nie.

Die basiese vertrekpunt van harmonisasie is dat dit nie afbreuk mag doen aan die stuwing, soepelheid en seggingskrag van die melodie nie. Dit staan immers in diens van die melodie.

\section{Laaste noot}

Die oerbetekenis van die woord "liriek" lê in die musiekinstrument die lier, en hierin lê die naelstringverbintenis tussen die poësie en die musiek. As die digter in Psalm 33:2a en 3 sê: "Loof die Here met die lier, ... Sing vir Hom 'n nuwe lied, speel met volle oorgawe, jubel dit uit!", moet dit die hartslag van die kerklied wees - 'n saamklop en -vloei van geloofsbloed in en deur die stramien van teologie, literatuur en musiek.

Die ryk tradisie van die kerklied moet steeds gekoester en tot nut van die gemeente gebruik word, maar nooit ten koste van vernuwing nie. Met die kerk van die eeue, maar ook as die kerk vir vandag, kan die kerklied in 'n lewende verhouding tussen bewaring en vernuwing, in 'n nog groter mate - soos Opperman ${ }^{45}$ gesê het - deur toesange en teensange op Hom laat weerklink die groot hosannas.

\section{NOTAS}

1. Vgl C Westermann, Ausgewählte Psalmen, Göttingen 1984, 17-18 en J A Burger, "Die Psalms" in Tweegesprek met God. Die literatuur van die Ou Testament. Deel 3 (Redakteurs J J Burden en W S Prinsloo), Kaapstad ${ }^{3} 1987,22-29$ oor die literatuursoorte van die Psalms.

2. C Albrecht, Einführung in die Hymnologie. Göttingen ${ }^{3} 1987,10 ; \mathrm{M}$ A Vrijland, Liturgiek, Meinema ${ }^{2} 1989,35-38$. 
3. C Albrecht, a.w., 10; C Trimp, De gemeente en haar liturgie, Kampen 1983, 91.

4. Vir 'n oorsig oor sekere aspekte van die geskiedenis van die lied deur die eeue tot in die twintigste eeu, vgl C Albrecht, a.w., 11-50.

5. Acta van die Algemene Sinode, Kaapstad 1986, 628.

6. Vgl L Strydom, "Die himnologiese betekenis van die 1978-gesangbundel" in 'n Geskiedenis van die Afrikaanse Protestantse Kerklied (Redakteur J H H du Toit), Pretoria 1983, 187-188.

7. E E Ryden, The story of Christian hymnody, Rock Island 1959, 3.

8. A C Barnard, "Die vrye Bybelse lied naas die psalms" in 'n Geskiedenis van die Afrikaanse Protestantse Kerklied (Redakteur J.H.H. du Toit), Pretoria 1983, 36.

9. Barnard, Die erediens, Pretoria ${ }^{2}$ 1985. 590.

10. Vgl. P Schelling, Loven met muziek. Zang en spel in Bijbel en kerk, Kampen 1986 , 110.

11. Teologie word hier nie in positivistiese sin verstaan nie, maar as 'n teologiese grondteorie is dit ' $n$ uitvloeisel van die verstaan van die Skrif, die belydenis en die kerklike en teologiese tradisie. Die verstaansproses bring mee dat die subjektiewe, die menslike nooit ontken kan word nie. In die verstaansproses is die Skrif egter steeds die norma normans.

12. Vgl. D J Smit, "Wat is gereformeerde spiritualiteit?", Ned Geref Teologiese Tydskrif Deel XXXIX Nommer 2 (1988), 182-192 en W D Jonker, "Die eie-aard van die gereformeerde spiritualiteit", Ned Geref Teologiese Tydskrif Deel XXX Nommer 3 (1989), 290-299.

13. Vgl Barnard, a.w. ${ }^{2} 1985,589-590$.

14. Albrecht, a.w., 37.

15. E C Pienaar, Die ontstaan van ons Afrikaanse Psalms- en Gesangeboek. Kaapstad 1944, 12.

16. F F Odendal, P C Schoonees, C J Swanepoel, S J du Toit \& C M Booysen, HAT: Verklarende woordeboek van die Afrikaanse Taal, Johannesburg ${ }^{3} 1983,209$.

17. F de Tollenaere \& A J Persijn. Van Dale nieuw handwoordenboek der Nederlandse taal. 's-Gravenhage ${ }^{8} 1977,230$.

18. Dit is wat $G$ van Wyk in sy "Ek sing n lolsang by my snare": die psalms as lied in die erediens (Pretoria 1979, 7) noem "uiting gee aan ons gemoed vanweè die goedertierenheid van die Here aan ons betoon."

19. A Flew, A dictionary of philosophy. London ${ }^{3} 1984,7$.

20. Vgl. M L Pratt, Toward a speech act theory of literary discourse, 1977, hfst. 1; T. Gouws, Die Transskriptuele lees. D.Litt-proefskrif PU vir CHO 1988, hist 3.

21. D M Wybenga, Diskoersanalise en stilistiek: 'n inleiding, Pretoria 1987, hfst. 3.

22. Barnard, a.w., 1983, 33.

23. Dit sou dan gebruiksliriek wees, 'n term van Erich Kästner wat Hennie Aucamp in sy Woorde wat word: geleentheidstukke oor randkultuur (Kaapstad 1984, 51) in Afrikaans bekendstel.

24. Die Afrikaanse evangeliese gesang: 'n literêre ondersoek, D. Litt.-proefskrif. UOVS 1969.

25. Hy praal oor die 1944-gesange.

26. Gaum, a.w., 104.

27. Gaum, a.w., 88-102.

28. Gaum, a.w., 102.

29. T T Cloete, "Die dromende denke van die digter" in SAVAL-kongresreferate, $\mathrm{nr} 4$, Pretoria 1984, 1-20.

30. Gaum, a.w., 102 stel dit egter ook eksplisiet: "'n Kommissie, bestaande uit persone met verskillende geaardhede, elkeen wat 'n deskundige op sy eie terrein is, kan nie 'n bevredigende gedig skep nie."

31. WE G Louw e.a., Die Gereformeerde kerklied deur die eeue, Kaapstad 1984, 6465.

32. M A K Halliday \& R Hasan. Cohesion in English, London 1976, 13. 
33. M P Beukes. Vooropstelling, kohesie en koherensie in die poèsie van T.T. Cloete, M.A.-verhandeling. PU vir $\mathrm{CHO} 1988$.

34. Pretoria 1989.

35. R Wellek \& A Warren, Theory of literature, ${ }^{3} 1980,127$.

36. Gaum, a.w., 103.

37. C van Heerden, "Die letterkundige aspek van die 1978-gesangbundel", in J H H du Toil, a.w., 178.

38. Aucamp, a.w., 52, en ook H du Toit, Popmusiek as kerkmusiek?, Pretoria 1979, 26.

39. $\mathrm{H}$ Haspers, Calvijns beginsel voor den zang in den eredienst (deel II), Den Haag 1976, 25.

40. Met dank aan dr. Wim Viljoen (departement Musiek, UP) vir sy kritiese aantekeninge by die lees van dié subafdeling.

41. Vgl. Strydom, "Sing onder mekaar - waarom hierdie proefsangbundel?", Vir die musiekleier 16 (1989), 7.

42. Vgl. O Herlyn, Singen unter den Zweigen. Erwägungen zu einem theologisch verantworteten Umgang mit neuen und alten geistlichen Liedern, Zürich 1986, 29.

43. Strydom, Vir die Musiekleier 116 (1989), 7.

44. Idem.

45. D J Opperman, Versamelde poësie, Kaapstad 1987, 226. 